\title{
Marcas dialógico-discursivas da linguagem e a constituição de sujeitos
}

\author{
Marcas dialógico-discursivas del lenguaje y la constitución \\ de sujetos
}

\section{Dialogical-discursive marks of language and the constitution of subjects}

Wilder Kleber Fernandes de Santana ${ }^{1}$

RESUMO: Intrínseca à concepção bakhtiniana de linguagem enquanto atividade essencialmente social e heterogênea, está a compreensão de sujeito, o qual é constituído pela alteridade. Numa perspectiva dialógico-enunciativa da linguagem, este estudo delimitou como objetivo analisar a concepção de sujeito construída a partir dos pressupostos de Bakhtin (1993, 2006a) e o Círculo (MEDVIÉDEV, 2016; VOLÓCHINOV, 2017). O presente trabalho, portanto, é de cunho bibliográfico-analítico, fundamentado nos dizeres dos pensadores do Círculo de Bakhtin, para reenunciar a linguagem e o sujeito dialógico, que ocupa múltiplos espaços sociais na existência e se constitui a partir do(s) outro(s). Em aspectos metodológicos, o trabalho está seccionado, além da Introdução, em: a) Compreensão dialógico-enunciativa da linguagem; b) Um sujeito de constituição alteritária e c) Entrevista como fenômeno discursivo de linguagem. Os resultados apontaram para a efetivação da identidade do sujeito por meio da abordagem do discurso, que não privilegia a forma dos enunciados, mas sobretudo a correlação entre conteúdo e discursos sociais.

PALAVRAS-CHAVE: Sujeito. Compreensão dialógico-enunciativa. Alteridade.

\footnotetext{
${ }^{1}$ Doutorando e Mestre em Linguística pela Universidade Federal da Paraíba (Proling-UFPB). Mestre em Teologia pela Faculdade Teológica Nacional (FTN) e Especialista em Gestão da Educação Municipal pela Universidade Federal da Paraíba (Pradime-UFPB). Membropesquisador do Grupo de Pesquisa em Linguagem, Enunciação e Interação (GPLEI-UFPB). Bolsista Capes. Contato: wildersantana92@gmail.com
} 
RESUMEN: Intrínseca a la concepción bakhtiniana del lenguaje como actividad esencialmente social y heterogénea, está la comprensión del sujeto, quien está constituido por la otredad. En una perspectiva dialógico-enunciativa del lenguaje, este estudio se propuso como objetivo analizar la concepción del sujeto construida a partir de los presupuestos de Bakhtin (1993, 2006a) y el Círculo (MEDVIÉDEV, 2016; VOLÓCHINOV, 2017). El presente trabajo, por lo tanto, es de cuño bibliográfico-analítico, fundamentado en las palabras de los pensadores soviéticos del Círculo de Bakhtin, para reenunciar al lenguaje y el sujeto dialógico, que ocupa múltiples espacios sociales en la existencia y se constituye a partir de los otros. En aspectos metodológicos, el trabajo se divide, además de la Introducción, en: a) Comprensión dialógico-enunciativa del lenguaje; b) Un sujeto con una constitución de otredad y c) Entrevista como fenómeno discursivo de lenguaje. Los resultados mostraron la efectividad de la identidad del sujeto a través del enfoque dialógico del discurso, que no privilegia la forma de los discursos, sino, sobre todo, la correlación contenido y los discursos sociales.

PALABRAS CLAVE: Sujeto. Comprensión dialógica-enunciativa. Otredad.

ABSTRACT: Intrinsic to the bakhtinian conception of language as an essentially social and heterogeneous activity is the understanding of the subject. In a dialogic-enunciative perspective of language, this study delimited to objective the conception of subject constructed from the presuppositions of Bakhtin (1993, 2006a) and the circle (MEDVIÉDEV, 2016; VOLÓCHINOV, 2017). The present paper, therefore, has a bibliographical-analytical character, based on the sayings of the Soviet thinkers of the Bakhtin circle, to re-enunciate the language and the dialogic subject that occupies multiple social spaces in the existence and is constituted from the other(s). In methodological aspects, the paper is divided, in addition to the Introduction, into: a) Dialogical-enunciative understanding of language for the constitution of subjects, b) $A$ subject with an altered constitution and c) Interview as a discursive language fenomenon. The results pointed to the effectiveness of the subject's identity through the discourse approach, which does not privilege the form of the statements, but above all the correlation between content and social discourses.

KEYWORDS: Subject. Understanding dialogic-enunciative. Otherness.

\section{Introdução}

Este trabalho circunscreve a concepção dialógico-enunciativa da linguagem em um espaço que, de forma específica, exigiu do pesquisador coerência com os postulados de sua produção e, além disso, o compromisso ético de fidelidade com o arcabouço teórico-metodológico da teoria. Nessa perspectiva, imbuídos dessa proposta, apresentamos o aporte teórico a partir do qual se 
deram as reflexões. Concordamos, assim, com Brait e Pistori (2012), as quais afirmam que é necessário haver um princípio de responsabilização por parte dos cientistas que mobilizam os discursos, seja didática ou academicamente, considerando-se suas dimensões históricas, socioideológicas e autorais.

Numa perspectiva dialógico-enunciativa da linguagem, dado um escopo do discurso ético-filosófico ${ }^{2}$, este estudo pretende analisar como a linguagem contribui para a constituição alteritária de sujeitos, a partir de pressupostos bakhtinianos (1993, 2006a) e dos membros do Círculo de Bakhtin ${ }^{3}$, tais como Medviédev (2016) e Volóchinov (2017). Tais formulações adquirem visibilidade num campo de investigação científica a partir de conceitos elaborados no âmbito do pensamento do Círculo. Coube-nos realizar um pequeno censo dos estudos realizados entre linguagem e sujeito sob prisma dialógico em terreno brasileiro, de forma que nosso enfoque de observação e delineamento epistêmico incidiu sobre estudos discursivos contemporâneos, a exemplo de Francelino (2007), Sobral (2009), Maciel (2014) e Santana (2019). Tais dizeres, por meio de estudos discursivos contemporâneos, ganham potencialidade na relação intersubjetiva ${ }^{4}$ entre tempo e espaço de produção, cujas abordagens conduziram-nos aos procedimentos de formulação teórico-metodológica do processo de sua tessitura.

O princípio dialógico-discursivo da linguagem convoca produções filosófico-sociológicas ao dele tratar enquanto instância plurivocal. Desse modo, nosso olhar procura superar evidências formais (e posições) pré-determinadas sobre materialidades discursivas, uma vez que instaura o sujeito sócioideológico

\footnotetext{
2 Esse escopo se instaura através das obras Para uma filosofia do Ato e Estética da Criação Verbal(BAKHTIN, 1993, 2006a).

${ }^{3}$ Conforme outrora pontuado por Santana (2019), quanto à expressão "Círculo de Bakhtin", faz referência a um grupo de intelectuais que se reuniu com frequência entre 1919 e 1929 em cidades russas, como Nevel, Vitebsk e São Petersburgo para debater sobre ideias e propostas filosóficas. Constituía-se por pessoas de áreas diversificadas e profissões distintas, dentre os quais se destacam Mikhail M. Bakhtin, Valentin N. Volóchinov e Pavel N. Medvedev. Outros integrantes eram Matvei I. Kagan, Ivan I. Kanaev, Maria V. Yudina e Lev. V. Pumpianski.

${ }^{4} \mathrm{Na}$ teoria bakhtiniana, a intersubjetividade é fundamental para a concretização de diálogos entre textos e discursos, produzidos por sujeitos responsavelmente preparados para enunciar seus dizeres. A intersubjetividade faz menção ao diálogo entre, no mínimo, duas consciências.
} 
e heterogêneo, a ocupar espaços sociais fronteiriços ${ }^{5}$, e cuja singularidade se dá no processo de enunciação.

Justifica-se nossa escolha em trabalhar com o gênero entrevista por reconhecermos sua potencialidade sintático-semântica de recepção/transmissão dos conteúdos, uma vez que tal configuração interessa ao analista do discurso tanto pela movência das vozes "outras" citadas nos enunciados quanto pela construção e organização discursiva. O gênero discursivo (BAKHTIN, 2006a; VOLÓCHINOV, 2017) entrevista é constituído como "uma constelação de eventos possíveis que se realizam como gêneros (ou subgêneros) diversos" (HOFFNAGEL, 2003, p. 180). Torna-se, portanto, imprescindível averiguar como os movimentos discursivos empreendidos no bojo do gênero entrevista podem promover uma conscientização político-ideológica, a fim de explicitar a importância de aderirmos a posicionamentos diante do social.

Para alcançar nosso objetivo, que é analisar a concepção de sujeito construída a partir dos pressupostos de Bakhtin (1993, 2006a) e o Círculo (MEDVIÉDEV, 2016; VOLÓCHINOV, 2017), traçamos um percurso estrutural: a) Compreensão dialógico-enunciativa da linguagem, a qual foi construída a partir das produções de Bakhtin e o Círculo. Depois, discorremos sobre o b) Um sujeito de constituição alteritária, e breves procedimentos metodológicos da pesquisa, o que nos conduziu a analisar uma c) Entrevista como fenômeno discursivo de linguagem para averiguar a manifestação da identidade alteritária do sujeito via instâncias dialógicas do dizer.

\footnotetext{
${ }^{5}$ A abordagem de fronteiras que trazemos é a defendida e mobilizada por Santana (2019, p. 81), em seu texto As fronteiras como espaço socio-axiológico, em que o autor pontua que "as fronteiras não indicam limites, mas possibilidades de novas compreensões, na medida em que oportunizam a interrelação entre uma multiplicidade de vozes. Além disso, saliente-se que, dada a inovação na concepção dialógica da linguagem, Bakhtin operou um deslocamento da noção de texto, em que o compreende por enunciado". Nesse sentido, esses espaços fronteiriços consistem em zonas vivas e concretas do texto condicionadas às diversas formas de diálogo, às réplicas encarnadas pela voz do(s) outro(s). Assim, para o autor, essa essência do texto-enunciado "se desenvolve na fronteira de duas consciências, de dois sujeitos" (BAKHTIN, 2006a, p. 310), fator que potencializa a linguagem e seus elementos integrantes (SANTANA, 2019).
} 


\section{Compreensão Dialógico-enunciativa de Linguagem}

Os encaminhamentos iniciais para nosso objeto de estudo partiram de uma reflexão de Bakhtin sobre a produção textual-discursiva nas ciências humanas, especificamente no texto Metodologia nas Ciências Humanas. Afirma o filósofo soviético que,

Se transformarmos o diálogo em um texto contínuo, isto é, se apagarmos as divisões das vozes (a alternância dos sujeitos falantes) o que é extremamente possível (a dialética monológica de Hegel) - o sentido profundo (infinito) desaparecerá (bateremos contra o fundo, poremos um ponto morto). (BAKHTIN, 2006b, p. 401).

Nesse instante, o filósofo soviético se posiciona contra a perspectiva formal, alertando que, caso haja um apagamento dos diálogos entre os discursos produzidos pelos sujeitos, ou seja, caso haja uma interrupção na cadência dialógica, os sentidos plurais desaparecem, e sobra apenas a significação hegemonicamente estabilizada. Para corroborar sua crítica, Bakhtin reporta-se à dialética monológica de $\mathrm{Hegel}^{6}$, a qual, imbuída do pensamento transcendentalista, estaria no plano do teoreticismo (desvinculação entre a vida e a arte, ou na separabilidade entre o plano abstrato das ideias de sua realidade histórica). Sobre os sentidos axiologicamente determinados entre sujeitos no processo de interação, atesta Bakhtin (2006b, p. 395-396) que "[...] o ser da expressão é bilateral: só se realiza na interação entre duas consciências (a do eu e a do outro); é o campo de encontro entre duas consciências, a zona do contato interior entre elas. "

\footnotetext{
${ }^{6}$ Ao circunscrever uma consciência que se concretiza em si mesma o teórico alemão Hegel defende, por meio da dialética, a necessidade de estimular o entendimento humano no escopo do transcendentalismo, cuja fórmula é: Eu penso. Em Fenomenologia do Espírito, Hegel $(1992$, p. 68) afirma que "o saber tem sua meta fixada tão necessariamente quanto a série do processo. A meta está ali onde o saber não necessita ir além de si mesmo, onde a si mesmo se encontra". Em apresentação à $2^{a}$ edição da referida obra, Henrique Vaz (1992, p. 18) comenta que o pensamento hegeliano desenrola-se no "fio dialético da experiência que mostra na "duplicação" da consciência-de-si em si mesma - ou no seu situar-se em face de outra consciência-de-si - o resultado dialético e, portanto, o fundamento da consciência do objeto".
} 
Em outras palavras, a unilateralidade (eu-para-mim) não provoca diálogos, logo conduz os sujeitos ao teoreticismo ou monologismo (BAKHTIN, 1993). Em contrapartida, o sujeito deve retornar a si em zona alteritária, especificamente em sua enunciabilidade, na esfera dialógica do discurso. No início de seus escritos, em Para uma Filosofia do Ato, na década de 1920, Bakhtin traz pela primeira vez seu pensamento acerca da conceituação de linguagem, aplicada aos atos humanos:

\begin{abstract}
Eu penso que a linguagem está muito mais adaptada a enunciar precisamente essa verdade, e não o momento abstrato da lógica em sua pureza. Aquilo que é abstrato, em sua pureza, é de fato não enunciável: qualquer expressão é muito concreta para o puro significado - ela distorce e ofusca a pureza e validade-em-si do significado. É por isso que no pensamento abstrato nós nunca compreendemos uma expressão em seu pleno sentido (BAKHTIN, 1993 p. 49).
\end{abstract}

Entendemos, portanto, que o discurso só ganha vida na forma de enunciações concretas de determinados falantes, os sujeitos do discurso. Não há um significado pleno para a linguagem, uma significação pura que a distinguia das demais manifestações comunicativas - ou até mesmo a essencialize. Ao contrário de um panorama abstrato, os enunciados concretos ocorrem a partir da alternância dos sujeitos dos discursos, e isso se dá porque o sujeito termina seu enunciado para passar a palavra ao outro (VOLÓCHINOV, 2017) tornandose um ser responsivo e participativo por tudo o que enuncia. Torna-se, assim, um agente produtor de sentidos dos discursos produzidos socialmente em situações concretas. Nesse prisma de interpretação,

Historicamente, a linguagem cresceu a serviço do pensamento
participativo e dos atos realizados, e começa a servir o pensamento
abstrato apenas em nossos dias. A expressão, do interior, de um ato
realizado, e a expressão do Ser-evento único e unitário no qual esse
ato é realizado, requerem a inteira plenitude da palavra: seu aspecto
de conteúdo (a palavra como conceito) tanto quanto seu aspecto
palpável expressivo (a palavra como imagem), e seu aspecto
emocional-volitivo (a entonação da palavra) em sua unidade. E em
todos esses momentos a palavra plena unitária pode ser
responsavelmente válida, isto é, pode ser a verdade [pravda] em vez 
de alguma coisa subjetivamente fortuita. (BAKHTIN, 1993, p. 49, grifo do autor).

Na perspectiva de Bakhtin, a língua passa a ser conceituada como instância de interação entre sujeitos sócio-historicamente situados. O pensamento participativo traz consigo o pressuposto de que há duas consciências que dialogam, e a palavra é plenificada na expressão do Ser-evento único e unitário que, ao enunciar, já dirige para outro e por causa de outro. Para alguns adeptos dessa linha de segmento a exemplo de Francelino (2007), os sujeitos, ao falarem, não apenas expressam sua cognição ou o fazem com propósitos comunicativos, mas, sobretudo,

[...] agem uns sobre os outros e produzem pontos de vista (posições axiológicas de sujeito). A língua é concebida como um sistema de formas em funcionamento, constituída por fatores externos como o contexto sociohistórico, a posição ideológica dos sujeitos falantes, enfim, os elementos linguísticos, que já vêm saturados pelas posições sócio-axiológicas de outrem, estão à disposição do sujeito para a produção dos mais diversos efeitos de sentido. (FRANCELINO, 2007, p. 34).

Para a constituição de nosso corte metodológico, é necessário pontuarmos a importância dos estudos desenvolvidos a partir do século $X X$, posto que Volóchinov (2017) e Medviédev (2016) estudiosos e membros atuantes do Círculo de Bakhtin, construíram, também, sua teoria do discurso posicionando-se axiologicamente contra as correntes linguístico-filosóficas hegemônicas nessa época.

Nos domínios extra acadêmicos, em que compreendemos os diálogos intercambiáveis entre Bakhtin e o Círculo, pensamento-ato, fazem-se imprescindíveis as projeções de Pável N. Medviédev, ao publicar, em 1928, O método formal nos estudos literários. Em seus escritos, apresentou rigorosas críticas ao formalismo europeu, especificamente o formalismo russo. Sua focalização, em busca do "reflexo do horizonte ideológico" (MEDVIÉDEV, 2016, p. 65), reenuncia a ideia de que a linguagem poética formalista tende ao niilismo 
artístico, ao imanentismo e ao apagamento do aspecto sociológico nos estudos literários (2016).

Ao contrário do sujeito uno cartesiano ${ }^{7}$, que vislumbrava a existência de uma consciência unívoca e coisificada para existir, na perspectiva sociológica (MEDVIÉDEV, 2016; VOLÓCHINOV, 2017), o sujeito existe participativamente, e, por meio da linguagem, os sentidos múltiplos se dão no entrecruzamento extraverbal. Os estudos sociológicos da linguagem, tendo como ponto de partida a interação discursiva (VOLÓCHINOV, 2017) prestam enfoque e visibilidade ao sujeito a partir de seus diálogos, de sua vivência em coletividade, em um processo mútuo de constituição.

Em contrapartida às perspectivas subjetivistas (Humboldt) e objetivistas (Sausurre), para Volochínov (2017), o que organiza a enunciação - atos de fala dos sujeitos - não é o interior subjetivo, com sua consciência individual, nem a estrutura interna do sistema linguístico, mas o exterior, o social, o extraverbal. Desse modo, na medida em que o pensamento inexiste distante de sua expressão potencial, "Toda compreensão é dialógica" (VOLOCHÍNOV, 2017, p. 232). Nesse fluxo semântico-discursivo, cuja interação propicia a constituição dos sujeitos na/pela linguagem, a compreensão "é determinada pelas fronteiras que se encontram na linha de contato desse enunciado com o meio extraverbal e verbal (isto é, com outros enunciados)" (VOLOCHÍNOV, 2017, p. 221).

Nessa linha interpretativa, faz-se imprescindível analisar os apontamentos realizados por Medviédev (2016, p. 49-50), para quem

Todos os atos individuais participantes da criação ideológica são apenas os momentos inseparáveis dessa comunicação e são seus componentes dependentes e, por isso, não podem ser estudados fora do processo social que os compreende como um todo. O sentido ideológico, abstraído do material concreto, é oposto, pela ciência burguesa, à consciência individual do criador ou do intérprete [...] Cada produto

\footnotetext{
${ }^{7}$ Santana e Lima $(2018$, p. 11) pontuam que em diversos momentos da história - o que pode ser encontrado em textos de Aristóteles, Descartes, Comte, Heidegger, Freud, por exemplo o processo de criação artística e/ou cientifica "foi idealizado como fruto de um ato individual do sujeito. Segundo essa ideia, um romance, um poema, uma pintura, ou ainda um tratado, um projeto medicinal, ou exame clinico psiquiátrico, partiriam de uma criação singular, isenta de qualquer influência externa que de algum modo pudesse incidir resultados sobre 0 ser/objeto/produto-processo".
} 
ideológico e todo seu "significado ideal" não estão na alma, nem no mundo interior e nem no mundo isolado das ideias e dos sentidos puros, mas no material ideológico disponível e objetivo, na palavra, no som, no gesto, na combinação das massas, das linhas, das cores, dos corpos vivos, e assim por diante.

Nesse direcionamento, quando se abordam as noções de dialogismo e interação, necessariamente falamos dos sujeitos, os quais são partes do processo de construção de sentidos. Ao analisarmos os trabalhos de estudiosos da teoria bakhtiniana da linguagem, em leituras mais detalhadas, percebemos que 0 Círculo de Bakhtin, na medida em que trata do sujeito social, também discute sobre o sujeito que apresenta sua individualidade.

É dessa forma que se estabelecem relações com outros sujeitos que o constituem e são constituídos por ele. Assim, o sujeito é pensado na interação social: é constituído em suas relações com outros sujeitos. Entender o sujeito na perspectiva de Bakhtin e o Círculo é imprescindível para esta análise, uma vez que o indivíduo é configurado como um Ser-Evento ${ }^{8}$ dotado de singularidade (sua insubstitutibilidade) no mundo por meio da linguagem.

As proposições basilares do princípio dialógico consistem na filosofia do diálogo ou da relação, de Martin Buber (2001) ${ }^{9}$. Ao afirmar a palavra como dialógica, o filósofo austríaco fundamenta a relação "entre" os seres humanos e propõe a vivência da interação - intersecção. Para essa ciência filosófica, 0 homem não é um ser individual, mas uma relação dialógica entre eu-tu, e assim inaugura-se o parâmetro do "tu" necessário para que haja diálogo. o "tu" é condição de existência do "eu", pois a realidade do homem é a realidade da diferença entre um "eu" e um "tu". O "eu" não existe individualmente, apenas existe como tradução de vida para o outro. Eis a origem da constituição do par

\footnotetext{
${ }^{8}$ A noção de Ser-evento, formulada e desenvolvida por Bakhtin (1993) faz referência ao ser humano que se constitui a partir de um outro responsavelmente, sem que fuja de seus deveres enquanto ser ético-ativo. Desse modo, institui o teórico russo outra categoria, o "nãoálibi na existência".

${ }^{9}$ Um dos principais sujeitos atuantes nas produções filosóficas acerca do diálogo como necessário para as relações humanas foi o austríaco Martin Buber, referenciado por Todorov (1981) como um dos pilares que influenciou o pensamento de Bakhtin sobre dialogismo. A principal obra de M. Buber, Ich und du, publicada em 1923, fora traduzida no Brasil em 1977 (Editora Moraes), nomeada "Eu e tu".
} 
fundador (não-dicotômico) - eu-outro. Ao pensarmos, por exemplo, em uma Lebensphilosophie ${ }^{10}$, não transcendental nem imanente, mas centrada na concretude da linguagem e do agir dos sujeitos, estamos imergindo no processoação de outras consciências, a filosofia e sua heterocientificidade, "metalinguagem de todas as ciências" (BAKHTIN, 2006b, p. 400)11.

Essa concepção de ressignificação do sujeito não pretende uniformizar os sujeitos da sociedade, pois como afirma Sobral (2009, p. 48), "o sujeito se divide em múltiplos papéis, nos termos de suas relações sociais, e a sociedade se divide em múltiplos grupos e segmentos, nos termos das relações entre esses grupos e segmentos. " Segundo Sobral (2009, p. 24), a filosofia do ato ético de Bakhtin é uma proposta de estudar o agir humano, um modus para compreensão teóricoprática de como os indivíduos agem no mundo concreto:

[...] um mundo social e histórico e, portanto, sujeito a mudanças, não apenas em termos de seu aspecto material, mas na maneira de os seres humanos o conceberem simbolicamente, isto é, o de representarem por meio de alguma linguagem, e de agirem nesses termos em circunstâncias específicas. (SOBRAL, 2009, p. 24).

A relação do homem/mundo - arte/vida, nessa perspectiva semânticodicotômica, não é vista apenas pelo aspecto natural (biológico), mas em termos de semiotização por meio da linguagem, em situações particulares, no interior dos mais diversos domínios da cultura imaterial.

\footnotetext{
${ }^{10}$ Filosofia da vida, cf. Sobral (2009, p. 8).

${ }^{11}$ Sobral (2009) nos ajuda a compreender que a proposta bakhtiniana estabelece, por exemplo, imersões na filosofia do Processo de Schelling (1775-1854) e na 'negação da empatia' de Hegel (1770-1831) com o intuito de complementá-las, uma vez que o idealismo alemão se constituiu por representar o subjetivismo da "filosofia da cultura". Nesse sentido, posto que os objetos estético-literários eram expressos apenas em níveis de abstração, tal qual uma ideia ou um conjunto circunstancial generalizado, um dos objetivos de Bakhtin foi propor uma análise com base na arquitetônica. De modo semelhante, Medviédev realiza críticas às propostas teórico-culturais de Henri Bergson (1859-1941) as quais se designará "estética expressiva" e "filosofia intuitiva da vida" (MEDVIÉDEV, 2016, p. 46).
} 


\title{
Um sujeito de constituição alteritária
}

A partir das proposições bakhtinianas, falar de atos é compreendê-los em dois planos indissolúveis: o agir humano geral e os atos particulares, que são englobados por aquele. Nesse fluxo enérgico, para Sobral (2009, p. 24),

\begin{abstract}
$\mathrm{O}$ ato como conceito é o aspecto geral do agir humano, enquanto os atos são seu aspecto como particular, concreto. Todos os atos têm em comum alguns elementos: um sujeito que age, um lugar em que esse sujeito age, e um momento em que age. Isso se aplica tanto aos atos realizados na presença de outros sujeitos como os atos realizados sem a presença de outros sujeitos, aos atos cognitivos que não tenham expressão linguística, etc. Falar de ato, portanto, pressupõe dois planos, um plano de generalidade, dos atos em geral, e um plano de particularidade, de cada ato particular, planos esses que estão necessariamente interrelacionados.
\end{abstract}

Bakhtin traz a necessidade de superar tanto o teoreticismo absoluto quanto o empirismo absoluto, não reduzindo o ato humano nem à abstração geral, nem às particularidades. Destarte, se por um lado "não admite que a teoria apague a vida concreta, prática, por outro, o autor também não admite que a prática concreta apague a teoria, o plano em que se pode generalizar sobre todos os atos" (SOBRAL, 2009, p. 26). No concernente à compreensão ativa, é preciso, segundo Bakhtin, evitar a separação entre conteúdo (produto), aspecto no qual nos é possível generalizar, e o processo, momento concreto, histórico e social do ato, aspecto que o torna único. Logo no início de "Para uma Filosofia do Ato", o teórico russo infere que

O momento que o pensamento teórico discursivo (nas ciências naturais e na filosofia), a descrição-exposição histórica e a intuição estética têm em comum, e que é de particular importância no nosso estudo, é este: todas essas atividades estabelecem uma cisão entre o conteúdo ou sentido de um dado ato-atividade, e a realidade histórica do seu ser, a real e única experiência dele. E é em consequência disso que o ato dado perde sua validade e a unidade de seu real devir e autodeterminação. (BAKHTIN, 1993, p. 19, grifo nosso).

A proposta filosófica dessa "dialética do produto-processo" (SOBRAL, 2009 , p. 26) sugere a experienciação de um (inter)agente. Por esse motivo, por 
não excluir o ser que realiza, é que esse processo se materializa no sujeito interdiscursivo. Caso não haja diálogo entre duas consciências, e apenas exista um ser e um ato (eu-para-mim), "apenas esse ato inteiro está vivo, existe completa e inescapavelmente - vem a ser, é completado. " (BAKHTIN, 1993, p. 20). Ainda que esse agente seja um participante real vivo em processo de Ser, e esteja em comunhão com a unidade única do Ser em processo, não se atinge um acabamento nem uma completude dialogada, pois

[...] essa comunhão ou participação não penetra seu aspecto de conteúdo-sentido, que pretende ser capaz de alcançar plena e definitiva auto-determinação dentro da unidade deste ou daquele domínio de sentido ou significado (ciência, arte, história), embora, como mostramos, esses domínios objetivos, separados do ato que os põe em comunhão com o Ser, não são realidades com respeito ao seu sentido ou significado. E como resultado, dois mundos se confrontam, dois mundos que não têm absolutamente comunicação um com o outro e que são mutuamente impenetráveis: o mundo da cultura e o mundo da vida [...] (BAKHTIN, 1993, p. 20, grifo nosso).

As proposições bakhtinianas engendram o agente como um elemento de extrema importância, pois o enxergam não apenas como aquele que realiza uma ação para adquirir aquela "realidade moral única e unitária como momento constituinte dela" (BAKHTIN, 1993, p. 20), mas que também produz um "pensamento participativo12" (BAKHTIN, 1993, p. 26), que permeia a relação entre o ato (em geral) e os atos particulares, instância-vetor em que este não pode ser separado de sua unicidade historicamente valorativa.

Ao tratarem da necessária correlação entre cultura e vida, Bakhtin (1993) e Medviédev (2016) afirmam que tais dimensões são indivisíveis, ao contrário do que concebiam as ciências naturais, filosofia da vida e estética formalista. 0 sujeito "não é aquele Ser único no qual nós vivemos e morremos, no qual se realizam nossos atos ou ações responsáveis; ele é fundamentalmente e essencialmente alheio à historicidade viva" (BAKHTIN, 1993, p. 26).

\footnotetext{
${ }^{12}$ Esse pensamento participativo, na ótica de Bakhtin (1993, p. 26), é o que tem predominância em todos os grandes sistemas de filosofia, "ou conscientemente e distintamente (em especial na Idade Média), ou de uma forma inconsciente e mascarada (nos sistemas dos séculos XIX e XX). "
} 
Conforme Santana (2019), quando o sujeito se engaja no discurso, (re)constrói sua identidade. Ele está, ao mesmo tempo em que se configura identitariamente, considerando o discurso do outro (ainda que discorde totalmente das opiniões alheias), visto que o sujeito ocupa na sociedade múltiplas identidades, pois está sempre em contato com diferentes interlocutores. Assim, por exemplo, ora o sujeito assume a identidade de político, ora de religioso, ora de professor e assim por diante. Então, a identidade do sujeito é compreendida como uma construção socialmente organizada por meio dos discursos. Conforme Faraco (2011, p. 25),

Por tudo isso, a ética bakhtiniana tem lá suas radicalidades: por ser único, por ninguém ocupar ou poder ocupar o lugar que ocupo, não tenho álibi para a existência - diz Bakhtin em Para uma filosofia (2010, p.96). Ou seja, eu não posso não agir, eu não posso não ser participante da vida real. Na vida, sou insubstituível e isso me obriga a realizar minha singularidade peculiar: tudo o que pode ser feito por mim não poderá nunca ser feito por ninguém mais, nunca. Assim, o dever encontra sua possibilidade originária lá onde reconheço a unicidade da minha existência e tal reconhecimento vem do meu próprio interior - lá onde assumo a responsabilidade da minha unicidade.

Faraco (2003) especifica a singularidade do sujeito, que, apesar de ser social, nunca é igual ao(s) outro(s), suas ações sempre o diferenciam e o constituem enquanto evento singular. É no dever para com seu outrem que pode se manifestar a eventicidade de sua responsabilidade. Assim, a abrangência da (in)acababilidade (est)ética do sujeito presume o reflexo integral, inteiro, artístico, ou seja, uma interrelação compreensiva-ativa, que é determinada pelo seu ativismo responsivo:

Mesmo que eu conheça inteiramente uma dada pessoa, e também a mim mesmo, eu ainda tenho de captar a verdade de nossa interrelação, a verdade do evento único e unitário que nos liga e do qual nós somos participantes. Isto é, o lugar e a função meus e dele, e nossa interrelação no evento do Ser em processo, isto é, eu mesmo e o objeto da minha contemplação estética devem estar determinados dentro do Ser unitário e único que nos abrange igualmente e no qual o ato da minha contemplação estética é realmente executada; mas isso não pode mais ser um ser estético. É apenas dentro desse ato como minha ação responsável que pode haver um caminho para a unidade do Ser, 
e não de seu produto, tomado em abstração. (BAKHTIN, 1993, p. 35, grifo nosso).

A concepção de sujeito, para o Círculo, consiste em que este assume um caráter de "responsabilidade/responsividade" e de "participatividade" que institui um aspecto responsivo do agente pelo seu ato. Este aspecto envolve o conteúdo e um dado processo por meio da valoração/avaliação responsável do agente pelo seu próprio ato, e o caráter responsivo a outros sujeitos que estão envolvidos neste ato. Nesse direcionamento, Sobral (2009, p. 54) afirma que, segundo o Círculo,

[...] o sujeito é essencialmente um agente responsável pelo que faz, agente que, em suas relações sociais e históricas com outros sujeitos igualmente responsáveis (inclusive apesar de si mesmos), constitui a própria sociedade sem a qual ele mesmo não existe.

Ao constituir um agente mediador entre os sentidos socialmente possíveis e os discursos produzidos em situações concretas, estabelece-se uma unicidade entre $o$ individual e o social. Sobre esse aspecto, faz-se importante também destacar que a realidade do sujeito se apresenta como um mundo de vozes sociais em diversas relações dialógicas: "relação de aceitação e recusa, de convergência e divergência, de harmonia e de conflitos, de intersecções e hibridizações. " (FARACO, 2003, p. 80). É nessas condições de produção de suas enunciações que o sujeito vai se "formando" discursivamente, pois vai apreendendo as vozes sociais, bem como suas inter-relações axio(dia)lógicas. Para compreender melhor o que se expôs, passemos à análise de uma entrevista, de teor dialógico-discursivo.

\section{Procedimentos Metodológicos da Pesquisa}

A entrevista se concretizou a partir da interação discursiva (VOLÓCHINOV, 2017) entre a defensora dos animais, Maria Luísa Lencastre, uma das Fundadoras do Projecto Ajuda Animal e a jornalista de ciência Renata Silva, sendo esses os 
sujeitos da pesquisa. A entrevista foi publicada em 21 de Dezembro de 2011 no portal eletrônico Mundo dos animais.

Os dados analisados foram gerados por meio de escolha seletiva, ou seja, após realizarmos uma comparação entre todas as questões enunciadas na entrevista, escolhemos as que melhor satisfizessem o objetivo da pesquisa, no sentido de analisar a concepção de sujeito construída a partir dos pressupostos de Bakhtin e o Círculo. Foi necessário perceber, no embate de vozes, quais respostas, por parte da entrevistada, demonstravam com mais nitidez seu posicionamento semântico-axiológico (BAKHTIN, 2006a) diante do outro, ou seja, desse auditório, Medviédev (2016), que a constitui. Tal critério está em consonância com a teoria que mobilizamos e que serve de suporte para o trabalho, uma vez que o filósofo russo Bakhtin (2006a) ressalta a necessidade de percebermos não apenas o horizonte ideológico presente em enunciações concretas, mas sobretudo os posicionamentos axiológicos assumidos pelos sujeitos no percurso dialógico-discursivo.

Quanto ao momento sociohistórico em que a entrevista ocorre, ou seja, em 2011, concretiza-se um cenário em que os maus tratos aos animais no Brasil atingiu seu apogeu, de forma que, alguns meses depois, no dia 25 de maio de 2012, "A Comissão Especial de Juristas encarregada de elaborar proposta para um novo Código Penal aprovou a criminalização do abandono de animais, além de tratamento mais severo para abusos e maus-tratos". (BRANDÃO, 2012). A entrevista se dá em um momento de efervescência político-ideológica em torno dos maus tratos e sobretudo abandono de animais. Acrescenta a redatora Gorette Brandão, na reunião dos juristas do Senado Federal.

Outro ponto que mereceu especial atenção dos juristas foi o tráfico de animais, com a sugestão de pena básica de dois a seis anos de prisão para atividades que hoje são punidas com prisão de seis meses a um ano, e multa. Pelo redesenho do tipo penal, será enquadrado como tráfico, entre outras hipóteses, importar, exportar, vender, expor à venda e manter em depósito, trazer e guardar o animal sem autorização legal. A proteção se aplica a ovos, larvas ou espécie da fauna silvestre nativa ou em rota migratória, bem como objetos feitos com matéria-prima animal, inclusive pena, pele e couros (BRANDÃO, 2012). 
É preciso, contudo, explicitarmos que enxergar a entrevista como um fenômeno discursivo de linguagem não consiste em um ponto de vista subjetivo, mas é o fruto da abordagem dialógica. Nesse prisma interpretativo, a entrevista não é tida apenas como um instrumento de comunicação entre indivíduos, e sim como um horizonte de compreensão, um dispositivo dialogal que permite a correlação histórico-ideológica entre as vozes e suas ressonâncias.

Em nossa análise, procuramos evidenciar como as enunciações de Maria Luísa Lencastre a constituem enquanto sujeito social, político, e não apenas enquanto indivíduo, ser empírico. Ainda que o corpus (enunciações) seja composto de (11) onze indagações, selecionamos para análise apenas duas (2) dessas perguntas, por entendermos que são exatamente essas que satisfazem ao propósito da análise. Além disso, devido às respostas serem muito extensas, fizemos um recorte, para especificidade de nosso ato analítico.

\section{Entrevista como fenômeno discursivo de linguagem}

Passemos, agora, à análise de algumas respostas da ativista e defensora dos animais Maria Luísa Lencastre, especificamente em suas réplicas durante a entrevista. A seguir dispõem-se as questões selecionadas da referida entrevista, assim como suas réplicas:

Quadro 1 - Fragmento da entrevista às Fundadoras do Projecto Ajuda Animal

\begin{tabular}{|l|l|}
\hline \multicolumn{2}{|c|}{ PROJECTO AJUDA ANIMAL } \\
\hline \multicolumn{1}{|c|}{ PERGUNTAS } & \multicolumn{1}{c|}{ RESPOSTAS } \\
$\begin{array}{l}\text { Quais são os } \\
\text { vossos principais } \\
\text { objetivos para } \\
\mathbf{2 0 1 2 ?}\end{array}$ & $\begin{array}{l}\text { São vários... dar "forma" a diversas parcerias. Temos sido contactadas } \\
\text { por diversas entidades / instituições que se mostram disponíveis para } \\
\text { nos ajudarem das mais diversas formas. Teremos de colocar por } \\
\text { escrito e em forma de compromisso - termos de responsabilidade - } \\
\text { estas preciosas ajudas que vão desde o apoio logístico a consultas, } \\
\text { alimentos, voluntariado, etc. }\end{array}$ \\
\hline $\begin{array}{l}\text { Quais os apelos } \\
\text { mais urgentes que } \\
\text { têm atualmente } \\
\text { em mãos? }\end{array}$ & $\begin{array}{l}\text { São vários os casos. Talvez mais prementes são as necessidades de } \\
\text { visitas ao veterinário, quer para tratamentos e vacinações, quer para } \\
\text { esterilizações. Também temos pedidos de comida para cães e para } \\
\text { gatos. Estes actos/ ajudas exigem dinheiro, exigem disponibilidade } \\
\text { para se ir buscar os animais, levar ao veterinário, pagar ao } \\
\text { veterinário, meter gasolina, limpar o carro... }\end{array}$ \\
\hline
\end{tabular}

Fonte: Lencastre (2011). 
Em resposta à primeira indagação, sobre "Os principais objetivos para 2012", a entrevistada, após dizer que existem vários, especifica alguns, e dentre estes está o concretizar as parcerias. Essa identificação primeira do grupo, como agentes que assumem a necessidade de outro(s) conferenciam a sua constituição alteritária. Após enunciar que o grupo tem sido contactado por diversas entidades que se disponibilizam a ajudar, a entrevistada focaliza o plano da responsabilidade como essencial à concretude dos propósitos grupo.

Mediante suas respostas, assim constituindo-se como defensora da causa animal, é constantemente valorada por suas escolhas linguístico-discursivas "temos", "teremos", o que denota o grau de comprometimento do sujeito (sem álibi na existência) com a causa que defende, ao convocar seus outros imediatos (suas parcerias). Esses eventos, projetos de ajuda à causa animal, são geridos como uma forma que os ativistas encontraram para atuar em defesa dos animais.

Para Sobral (2009, p. 26), "as práticas supõem grupos humanos, não sujeitos isolados". Logo, cada ato realiza-se mediante diálogos entre consciências concretas. Essa responsividade/responsabilidade ética do(s) sujeito(s) é confirmada, por exemplo, quando Bakhtin promove a encarnação do "não-álibi na existência", ou melhor, quando diz que "viver a partir de si não significa viver para si, mas significa ser, a partir de si, responsavelmente participante, afirmar o seu não-álibi real e compulsório no existir" (BAKHTIN, 1993, p. 108), pois cada ato-sujeito é constituinte de sua responsabilidade.

No que diz respeito especificamente aos aspectos alteritários constituintes da entrevista, é pertinente mencionar que unicidade real é concretizada na medida em que há um eu, enquanto sujeito responsivo-ativo, que se propõe a sair-de-dentro-de-si (cf. BAKHTIN) e adentrar no mundo alheio. Após adentrar nesse mundo, o sujeito não permanece no outro, mas retorna a si, com aprendizados que adquiriu, ou seja, com certo excedente de visão. Assim, ao discutir filosoficamente sobre o processo empático de vivência alteritária, Bakhtin compreende que,

"A centralidade da minha participação única no Ser, dentro da arquitetônica do mundo realmente experimentado, não consiste na 
centralidade de um valor positivo para o qual tudo o mais no mundo seria apenas um fator auxiliar" (BAKHTIN, 1993, p. 78, grifo nosso).

Diante dos argumentos supranarrados, inferimos que tais gestos de descentralização não são feitos de forma aleatória, mas carregados de relações cronotópicas as quais agregam centros de valor em torno de atos estrategicamente elaborados.

Na ótica de Maria Luísa Lencastre, as ajudas são preciosas, uma vez que potencializam os propósitos do Projecto Ajuda Animal, os quais se estendem desde $o$ apoio logístico a consultas, alimentos, voluntariado etc. faz-se importante notar que, enquanto enuncia, o sujeito assinala sua individualidade. Em meio a tantos outros, apenas ela pode tomar essa posição, e enunciar dessa forma, com esses trejeitos e movências ético-racionais.

Esse sujeito que toma individualidade, na verdade, não se direciona para uniformização/generalização, pelo contrário, reintegra outros sujeitos da sociedade. Há relações dialógicas de concordância, por exemplo, com Maciel (2011), em sua obra Pensar/escrever o animal: ensaios de zoopoética e biopolítica. Nesse seu escrito, a autora compreende que se torna possível promover efeitos de conscientização humana diante da natureza e dos animais, por meio de uma biopolítica direcionada para as interrelações entre o humano e meio ambiente. De modo semelhante, ecoam as vozes de Singer (2008), ao problematizar o uso e a exploração dos animais não-humanos na indústria de experimentação, e de Francione (2013, p. 27), defensor do "Abolicionismo Animal", para quem "A razão da profunda inconsistência entre o que dizemos sobre os animais e como realmente os tratamos é o status, ou a condição, dos animais como nossa propriedade. "

Nesse sentido, como afirma Sobral (2009, p. 48), "o sujeito se divide em múltiplos papéis, nos termos de suas relações sociais, e a sociedade se divide em múltiplos grupos e segmentos, nos termos das relações entre esses grupos e segmentos. " Então, quando o sujeito se engaja no discurso, (re)constrói sua identidade. Assim, em continuidade, Renata Silva indaga: Quais os apelos mais urgentes que têm atualmente em mãos? Mais uma vez, através do termo 
"vários", percebemos existir, por parte da entrevistada, uma multiplicidade de atos que são necessários para a manutenção e a corporificação do projeto. Assim, Maria Luísa Lencastre especifica: necessidades de visitas ao veterinário, quer para tratamentos e vacinações, quer para esterilizações. Além desses atos de teor mais imediato, existem os pedidos de comida para cães e para gatos.

Na segunda instância enunciativa, a própria entrevistada atribui sentidos axiológicos aos atos que estão sendo convocados para mobilização social em favor da causa animal. Estes actos/ ajudas exigem dinheiro, exigem disponibilidade para se ir buscar os animais, levar ao veterinário, pagar ao veterinário, meter gasolina, limpar o carro... esse vocativo ecocrítico instaura diálogo com dois auditórios: o auditório de animais não-humanos, que é a causa de preocupação imediata, e o auditório humano, que precisa, mutuamente, se ajudar. As enunciações de Maria Luísa Lencastre, portanto, demonstram sua 'posição sujeito de ativista e defensora da causa animal' enquanto evento responsivo ativo, a qual está lutando por outros seres.

A respeito do sujeito, conforme Sobral (2009, p. 56), "ele não age sozinho, mas não deixa de ser ele mesmo, nas várias 'posições-sujeito', nos diferentes papéis que assume diante de diferentes interlocutores". Em outras palavras, podemos dizer que o sujeito do discurso ocupa um lugar social a partir de onde enuncia, e é este lugar, compreendido como lugar do religioso, do sexólogo, do político, do docente, do publicitário, por exemplo, que determina o que ele pode ou não dizer a partir dali. No caso específico da entrevistada Maria Luísa Lencastre, ela assume o papel de cuidadora dos animais e de ativista em defesa de seus direitos. A responsabilização que vemos em seus atos remontam não apenas ao lutar pela causa, mas ao compartilhar disso com outras pessoas, performando um diálogo de consciências. Nesse direcionamento, ao ocupar o lugar social de ativista e defensora dos animais, Lencastre se torna uma voz de autoridade, uma entidade representativa e símbolo da defesa animal.

Esse sujeito, a partir do instante em que ocupa o interior de uma esfera social, é dominado por uma determinada ideologia. Esta, por sua vez, estabelece previamente as possibilidades de sentido de seu discurso. Vale salientar, por fim, 
que este sujeito não está submetido à sociedade nem à história como um fantoche. Não age submetido a elas totalmente, nem tampouco de si para si, mas torna-se um agente mediador inserido na sociedade e na história, em processo, um vir-a-ser.

\section{Considerações Finais}

Ao longo do trabalho, pudemos observar como a linguagem, sob perspectiva de Bakhtin e o Círculo, contribui para a construção social do sujeito, em contraposição ao que era imperante em notação cartesiana. Na ótica discursiva dos pensadores russos do Círculo de Bakhtin, o sujeito é responsivo, constituído dialógico-enunciativamente, em camadas sócio-históricas, e não o sujeito uno, individual.

Em nosso ato analítico, averiguamos que as enunciações da entrevistada Maria Luísa Lencastre demonstra um ato responsivo ativo, no âmbito das noções de ato e de linguagem propostas por Bakhtin, na medida em que aquela submete seu discurso a forças históricas, centralizadoras, centrípetas, decorrentes dos processos de centralização sociopolítica e cultural e, ao mesmo tempo, colide com estas forças através de vetores descentralizadores, massas centrífugas, que conduzem a uma densidade de vozes dialogizada.

A efetividade do processo de construção da alteridade no material analisado se dá em cada gesto enunciativo que dá visibilidade não apenas ao auditório imediato (MEDVIÉDEV, 2016), mas a todos os sujeitos envolvidos na enunciação. Um exemplo está na menção à necessidade de se colocar por escrito e em forma de compromisso os termos de responsabilidade, o que pressupõe, acima de fatores puramente teóricos, um posicionamento responsivo ativo por parte da ativista Lencastre. Dentre outras questões, esses atos refletem o cuidado com todo o processo gestacional do projeto, a que estão vinculadas consciências plurais.

Acreditamos, por fim, ter cumprido os propósitos da pesquisa: o de analisar como Bakhtin e o Círculo teceram os fundamentos para o princípio 
dialógico da linguagem e do sujeito, tanto em bases filosóficas (BAKHTIN, 2006a) quanto sociológica (MEDVIÉDEV, 2016; VOLOCHÍNOV, 2017). Enfatizamos que é por meio de horizontes dialógicos no plano da alteridade que o sujeito se instaura.

\section{Referências}

BAKHTIN, Mikhail M. Estética da criação verbal. Tradução de Paulo Bezerra. 5. ed. São Paulo: Martins Fontes, 2006a. Tradução da versão russa. [1979].

BAKHTIN, Mikhail M. Metodologia das ciências humanas. In: BAKHTIN, Mikhail M. Estética da criação verbal. Tradução de Paulo Bezerra. 5. ed. São Paulo: Martins Fontes, 2006b. p. 393-410. Tradução da versão russa. [1979].

BAKHTIN, Mikhail. Para uma filosofia do ato. Tradução inédita de Carlos Alberto Faraco e Cristóvão Tezza. Tradução sem revisão, destinada ao uso didático, da edição americana: Touard a Philosophy of the Act. Austin: University of Texas Press, 1993. [1920-1924].

BRAIT, Beth; PISTORI, Maria Helena Cruz. A produtividade do conceito de gênero em Bakhtin e o Círculo. Alfa, São Paulo, v. 56, n. 2, p. 371-401, 2012.

BRANDÃO, Gorette. Seis anos de cadeia para quem maltratar e matar animais. Senado Notícias, Brasília DF, 25 maio 2012. Notícias. Disponível em: https://www12.senado.leg.br/noticias/materias/2012/05/25/seis-anos-decadeia-para-quem-maltratar-e-matar-animais. Acesso em: 2 maio 2020.

BUBER, Martin. Eu e tu. Tradução de Newton Aquiles Von Zuben. 10. ed. São Paulo: Centauro, 2001. Tradução da versão alemã.

FARACO, Carlos Alberto. Aspectos do pensamento estético de Bakhtin e seus pares. Letras de Hoje, Porto Alegre, v. 46, n. 1, p. 21-26, jan. /mar. 2011.

FARACO, Carlos Alberto. Linguagem e diálogo: as ideias linguísticas do Círculo de Bakhtin. Curitiba: Criar Edições, 2003.

FRANCELINO, Pedro Farias. $A$ autoria no gênero discursivo aula: uma abordagem enunciativa. 2007. Tese (Doutorado em Letras) - Universidade Federal de Pernambuco, Recife, 2007.

FRANCIONE, Gary L. Introdução aos direitos animais. Tradução de Regina Rheda. Campinas: Editora Unicamp, 2013. [1954].

HEGEL, Georg Wilhelm Friedrich. Fenomenologia do espírito: parte I. Tradução de Paulo Meneses com colaboração de Karl-Heinz Efken. Petrópolis: Editora Vozes, 1992. 
HOFFNAGEL, Judith Chambliss. Entrevista: uma conversa controlada. In: DIONÍSIO, Ângela Paiva; MACHADO, Anna Rachel; BEZERRA, Maria Auxiliadora (org.). Gêneros textuais e ensino. Rio de Janeiro: Lucerna, 2003. p. 180-193.

LENCASTRE, Maria Luísa. Entrevista às fundadoras do Projecto Ajuda Animal. [Entrevista cedida a] Renata Silva. Mundo dos Animais, Porto, PT, 21 dez. 2011. Entrevistas. Disponível em:

https://www.mundodosanimais.pt/entrevistas/projecto-ajuda-animal/. Acesso em: 28 jun. 2018.

MACIEL, Maria Esther (org.). Pensar/escrever o animal: ensaios de zoopoética e biopolítica. Florianópolis: Editora da UFSC, 2011.

MACIEL, Suely. Comunicação radiofônica e interatividade à luz do dialogismo e da interação verbal. In: SIMIS, Anita; BRUNELLI, Anna Flora; REBECHI JUNIOR, Arlindo; NAPOLITANO, Carlo José; GONZALES, Lucilene dos Santos; GOBBI, Maria Cristina; MACIEL, Suely. (org.). Comunicação, cultura e linguagem [online]. São Paulo: Editora UNESP: Cultura Acadêmica, 2014. p. 79-105. (Desafios contemporâneos collection).

MEDVIÉDEV, Pável Nikoláievitch. O método formal nos estudos literários. introdução a uma poética sociológica. Tradução de Sheila Camargo Grillo e Ekaterina Vólkova Américo. São Paulo: Contexto, 2016. [1928].

SANTANA, Wilder Kleber Fernandes de. Relações linguísticas e axio(dia)lógicas. sobre linguagem e enunciação. João Pessoa: Ideia, 2019.

SANTANA, Wilder Kleber Fernandes de; LIMA, Pablo Vinícius de Brito. Bakhtin e o Círculo: entornos dialógico-discursivos sobre o ato e a alteridade. Revista Versalete, Curitiba, PR, v. 6, n. 11, p. 8-25, jul. /dez. 2018.

SINGER, Peter. Libertação animal. Tradução de Marly Winckler. Porto Alegre, São Paulo: Lugano, 2008. [1975].

SOBRAL, Adail. Do dialogismo ao gênero: as bases do pensamento do Círculo de Bakhtin. Campinas: Mercado de Letras, 2009.

VAZ, Henrique Cláudio de Lima. Apresentação. In: HEGEL, Georg Wilhelm Friedrich. Fenomenologia do espírito: parte I. Tradução de Paulo Meneses com colaboração de Karl-Heinz Efken. Petrópolis: Editora Vozes, 1992. p. 18.

VOLÓCHINOV, Valentín Nikoláievitch. Marxismo e filosofia da linguagem: problemas fundamentais do método sociológico na ciência da linguagem. Tradução de Sheila Grillo e Ekaterina Vólkova Américo. São Paulo: Editora 34, 2017. Círculo de Bakhtin. [1929]. 